\title{
PERFORMANCE ASSESSMENT OF DAMAGED BRIDGE BENTS AFTER THE LOMA PRIETA EARTHQUAKE
}

\author{
M. J. N. Priestley ${ }^{1}$ and F. Seible ${ }^{2}$ \\ This paper was presented at the Pacific Conference on Earthquake Engineering \\ New Zealand, November 1991
}

\begin{abstract}
SUMMARY
Following the October 17, 1989 Loma Prieta Earthquake, a large number of damaged and undamaged structural concrete bridge structures had to be assessed and evaluated for seismic repair and retrofit. The lack of consistent assessment and evaluation models prompted the formulation of the outlined procedures in a first attempt to develop a comprehensive basis for the seismic assessment and retrofit of existing bridge structures. The presented principles are currently being developed at UCSD into consistent assessment design models in cooperation with the California Department of Transportation.
\end{abstract}

\section{INTRODUCTION}

The Loma Prieta (San Francisco) earthquake of October 17, 1989 reemphasized the vulnerability of structural concrete systems to cyclic loads and displacements resulting from seismic attack. While the dramatic collapse (see Fig.1a) of a one-mile section of the Cypress Viaduct collapse was well publicized in the press and technical literature, only limited information can be found on extensive structural damage to other elevated roadways in the San Francisco-Oakland Bay Area (see Fig.2) which led to the temporary or permanent closure of several major freeway arteries including the Embarcadero Viaduct (I-480), the China Basin/Southern Freeway Viaduct (I-280) and the Central Viaduct (Highway 101) in San Francisco, as well as the Southbound Connector (I-980) in Oakland [1].

While most of these damaged bridges were designed and built in the 1950's and 1960's, some of them were designed and completed as late as 1985 . This raises questions concerning not only past but current detailing practice for structural concrete systems. Analytical models to study the in-depth mechanism of structural concrete behaviour through various limit states and design models developed to unify the structural detailing and design approach have seen comprehensive recent developments. In a direct extension of early structural concrete design principles by Ritter (1899) and Mörsch (1909), Schlaich et al. have developed a comprehensive design approach toward structural concrete detailing which ensures internal force transfer through discrete compression and tension (strut and tie) members, satisfying equilibrium by simple truss mechanisms [2]. This approach has become a powerful design tool since it allows a variety of detailing solutions as long as basic anchorage and stress limit states are observed, but most importantly it

${ }^{1}$ Professor, University of California, San Diego, USA

(Fellow and Past President)

${ }^{2}$ Professor, University of California, San Diego, USA. allows and forces the design engineer to develop a consistent design model resulting in an engineered solution based on equilibrium principles rather than in a design based on a recipe application. Problems and limitations arise when design solutions based on inappropriate truss mechanisms are attempted and when the discrete member forces are of magnitudes which cause stress limit and anchorage problems and thus require a distributed or smeared approach. Parallel to the consistent strut and tie model development, Collins et al. developed the juxtaposed position of a smeared or distributed behaviour model [3], which is based on homogeneous behaviour of structural concrete even in its cracked state and resulting orthogonal principal compression and/or tension fields of the internal forces. Based on mechanical principles of an orthotropic homogeneous material, the orientation of the resulting stress fields is derived from compatibility and equilibrium conditions. The resulting stress fields are subsequently discretized in unidirectional concrete and reinforcement action forming the basis for a rational structural concrete design approach, capturing realistic stiffness and deformation limit states. Similar to the discrete strut and tie model, additional considerations for anchorage and local concentrated force transfer are required and limitations exist where either reinforcement is heavily concentrated rather than distributed, and where structural action results in a few large cracks rather than in the ideal distributed (smeared) crack pattern. Thus, while both design models are different in the approach, they are rather complementary in the overall design process, especially when in addition to the force transfer in the joint or member, deformation limit states also need to be considered.

Both of the above models provide comprehensive design approaches to structural concrete detailing but are fully applicable only when simple monotonic loading conditions exist up to service load levels with sufficient margin to the ultimate limit state. Where deteriorating bond phenomena along the reinforcement, in anchorage zones or lap splices, opening and closing of cracks under fully reversed cyclic loading, deterioration of concrete contribution in developing local failure 

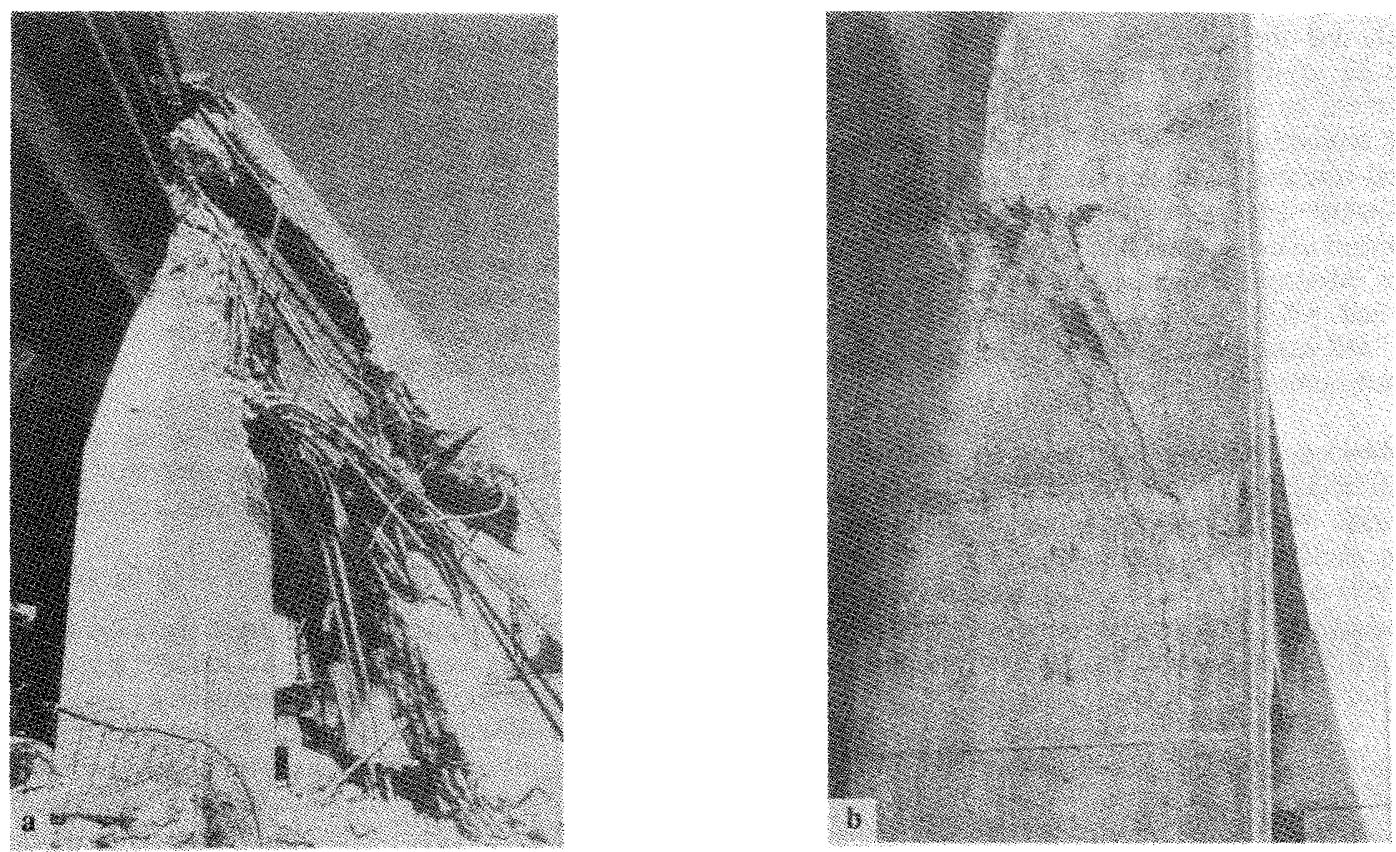

FIGURE 1 Cypress Viaduct Collapse and Embarcadero Distress Patterns.
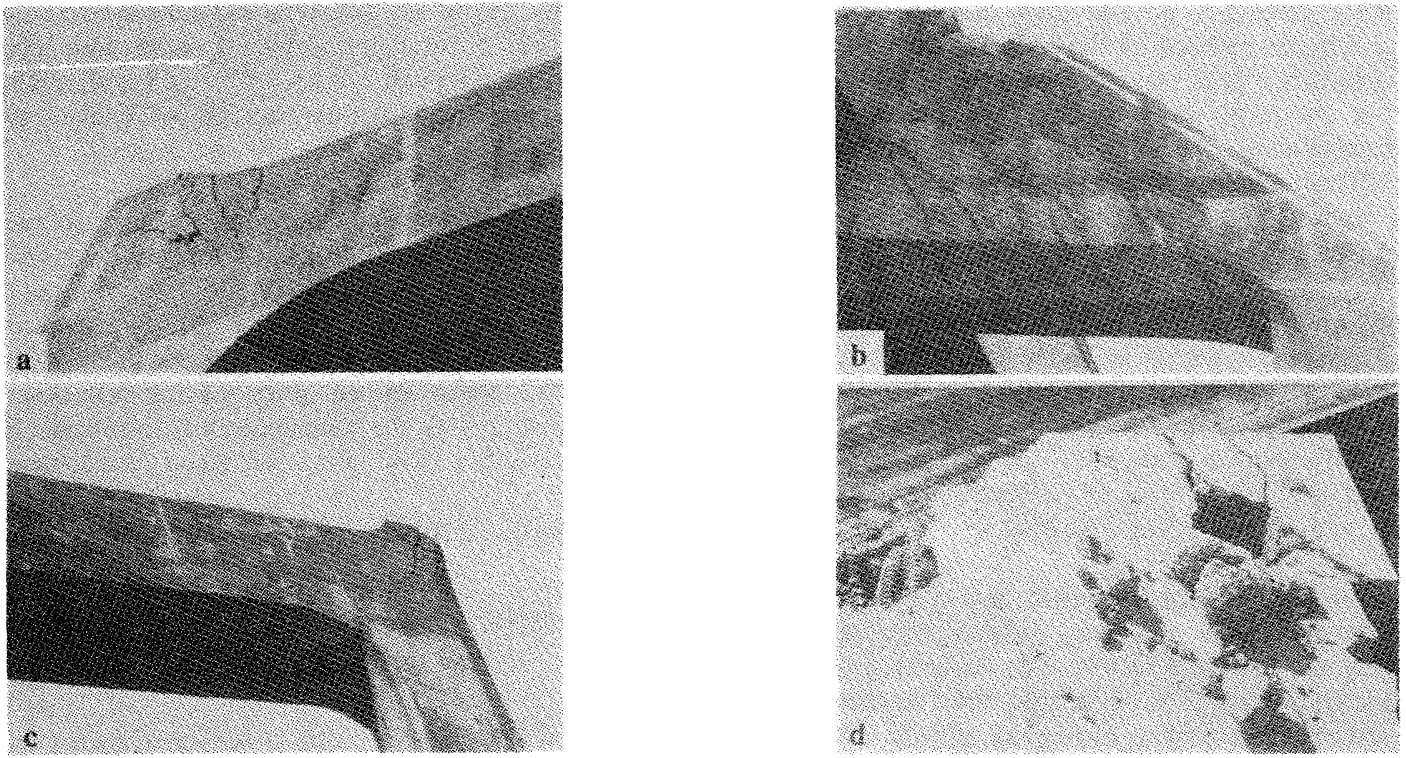

FIGURE 2 Outrigger Bent Damage. 
mechanisms, and the development of ductile hinges (which incorporate all of the above aspects) are present, the above models may not be adequate and additional considerations to both design approaches are needed as outlined by Paulay et al. for structural concrete joints under seismic action [4]. Thus, for realistic damage and performance assessment of existing concrete bridges under seismic loads, different types of models need to be developed which are based on actual material properties and reflect deteriorating bond phenomena, yield penetration, and reduction of concrete shear contribution under fully reversed cyclic loading patterns.

In the following, examples of concrete bridge damage encountered during the 1989 Loma Prieta earthquake are used to demonstrate design deficiencies and methods to assess encountered damage, ranging from quick capacity checks to nonlinear finite element analyses. Based on these studies, an evolving assessment procedure is outlined to determine the actual state of existing concrete bridges and to support seismic retrofit decisions.

\section{DAMAGE ASSESSMENT}

The collapse of the Cypress Viaduct in Oakland was caused by inadequate structural detailing, particularly of the lower capcolumn joint region. A typical failed bent of the Cypress Viaduct in shown in Fig. 1a, while probably more instructively, Fig. $1 \mathrm{~b}$ depicts the joint distress pattern of the cap-column joints in the Embarcadero Viaduct and in portions of the Cypress Viaduct which did not collapse during the Loma Prieta earthquake. Vertical and horizontal joint reinforcement detailing was inadequate to transmit the required joint shear forces, and both a capacity design check with a joint equilibrium model and a compression-field based nonlinear finite element model [1] predicted shear strengths of less than $1.8 \mathrm{MN}$ (400 kip), sufficient to fail the pedestal in the joint region. While the simple equilibrium check on the joint provides a quick assessment of the joint shear capacity, the nonlinear finite element investigation of the joint also provides the sequential crack and yield development patterns and associated deformation limit states which allow estimates of the ultimate failure mode, as shown in Fig.3.

While the Cypress failure originated in the lower cap column joint region, distress patterns encountered in other elevated roadways such as the China Basin Viaduct (I-80) and the Oakland Southbound Connector (I-980) show extensive capbeam and joint distress, particularly in the knee joints of outrigger bents as shown in Fig. 2. These outrigger bent damage patterns will be evaluated in the following.

An overview of the China Basin Viaduct bent $\mathrm{N}_{1}-35$ geometry, reinforcement layout and cap-beam moment capacities and demands are given in Figs. 4 and 5. The upper roadway $\left(\mathrm{N}_{1-}\right.$ line) is supported by a large outrigger bent which sustained both joint shear and cap flexural/shear damage as outlined in Figs. $2 a$, $\mathrm{b}$ and $\mathrm{c}$. To assess the expected seismic performance of bent $\mathrm{N}_{1}-35$, dead load moments and flexural capacity of the upper cap beam and columns was estimated and are summarized for the cap beam in Fig.5, based on the as-built dimensions and reinforcement details depicted in Fig.4. For bent $\mathrm{N}_{1}-35$, the flexural capacities of the cap beam were well below the column capacities and were thus critical for the overall seismic performance assessment. A unit lateral (seismic) force was subsequently applied to the bridge bent model, and scaled to levels $E_{1}$ and $E_{n}$, where sequential mechanisms would form based on the derived capacity envelopes.
Lateral response force levels of $\vec{E}=0.63 \mathrm{~g}$ and $\stackrel{\leftarrow}{\mathrm{E}}=0.69 \mathrm{~g}$ in the two directions, respectively, were found to cause complete global flexural mechanisms to develop. Particularly under loading to the right, (see Figs. 4 and 5), the termination of negative or top reinforcement at a distance of $6.1 \mathrm{~m}$ from the column centerline is cause for the onset of a negative moment crack which propagates toward the column in shear aided by the lack of cap beam shear reinforcement in this region, see Fig.4. A wide flexural-shear crack was observed in this region, as predicted, and may be seen in Fig. $2 \mathrm{~b}$.

Joint shear cracking was calculated for both joints to occur at lateral force levels less than those corresponding to the first hinge formation. Approximate values corresponding to a joint

shear stress of $0.33 \sqrt{\mathrm{f}_{\mathrm{c}}^{\prime}} \mathrm{MPa}$ are $\overrightarrow{\mathrm{E}}=0.45 \mathrm{~g}$; and $\stackrel{\leftarrow}{\mathrm{E}}=0.40 \mathrm{~g}$, respectively. Thus, significant joint shear distress, as seen in Figs. $3 a$ and $c$, can be expected. While the level of cracking visible in the positive knee joint moment regions of the bent cap beam indicates that the cap did not reach first hinge formation, the shear stresses in the joints were high enough to cause joint failure. Hence the response accelerations appear to have exceeded $0.4 \mathrm{~g}$ in each direction. However, both cap beam and joint mechanisms form at very similar lateral load levels and the distress pattern in the cap beam also indicates reinforcement inadequacies. As a consequence, complete replacement of the entire bent was recommended [1], rather than repair and strengthening.

A single-deck outrigger bent (bent \#38) with only $1 \mathrm{~m}$ outrigger cap beam extension past the superstructure on I-980 featured heavy joint damage as shown in Fig.2d. Built in 1985, the rectangular column was well confined with interlocking spirals, (see Fig.6). However, this spiral did not continue into the joint region where it was replaced by a 5 gauge wire spiral with $\phi$ $5 \mathrm{~mm} @ 100 \mathrm{~mm}$ pitch. Also, the cap beam reinforcement, except for the top and bottom bars did not extend into the joint region.

A capacity check on the cap beam and column capacities showed that the cap beam capacity is critical for positive moment due to the insufficient anchorage length of $1.8 \mathrm{~m}$ for the \#18 bars $(57 \mathrm{~mm} \phi)$ which, based on ACI $318-89$, require a basic development length of $3.0 \mathrm{~m}$. This is likely to be on the conservative side. In the other loading direction (negative moment in the joint), the column capacity is critical. Joint shear capacity demands show joint shear stress levels corresponding

to nominal flexural capacity of $0.36 \sqrt{\mathrm{f}_{\mathrm{c}}^{\prime}}(\mathrm{MPa})$ and

$0.5 \sqrt{\mathrm{f}_{\mathrm{c}}^{\prime}}(\mathrm{MPa})$, under positive and negative moment, respectively, which are both above an assumed level of

$0.3 \sqrt{f_{\mathfrak{c}}^{\prime}}(\mathrm{MPa})$, where diagonal tension cracking in the joint can be expected. Since the shear capacity of the 5 gauge wire spiral in the joint region does not add significant joint shear capacity, the formation of any flexural hinge mechanism in adjacent members was inhibited by premature joint failure. This explains the diagonal joint crack patterns encountered during the Loma Prieta earthquake.

In addition to the diagonal crack patterns, large areas of cover concrete spalled along the outer cap corner, (see Fig.2d), and a \#18 reinforcement bar which was bent on a $450 \mathrm{~mm}$ radius ruptured (see Fig.6). The first phenomenon of cover concrete 

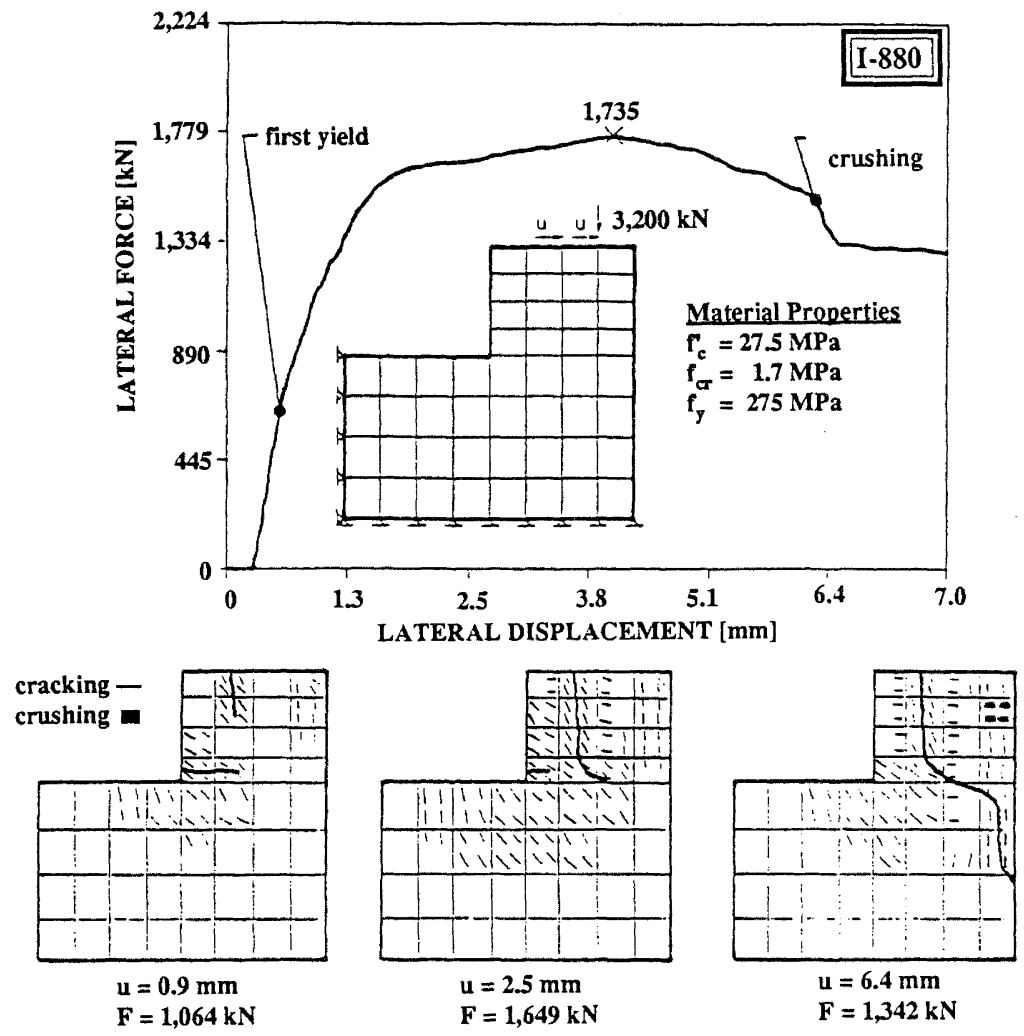

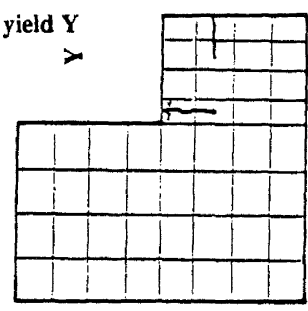

$\mathrm{u}=1.7 \mathrm{~mm}$

$\mathbf{F}=1,575 \mathrm{kN}$

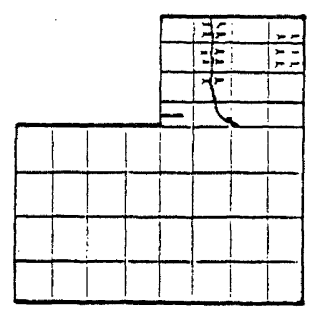

$\mathrm{u}=2.5 \mathrm{~mm}$

$\mathrm{F}=1,659 \mathrm{kN}$

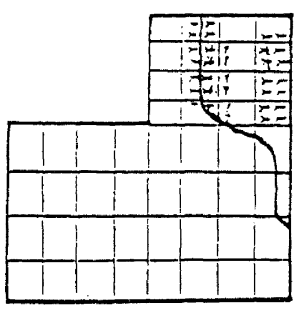

$\mathrm{u}=6.4 \mathrm{~mm}$

$\mathrm{F}=1,342 \mathrm{kN}$

FIGURE 3 Load-Deformation History and Distress Pattern Development in Lower Cap-Column Joint of the Cypress Viaduct.

spalling can be explained as a consequence of the reversed cyclic loading. Under negative moment, flexural cracks open at the cap top. Under reversed loading high compression forces in the top reinforcement transferred to the concrete by bond, have a tendency to spall off the concrete cover between flexural cracks developed in the previous tensile excursions. The second phenomenon, the ruptured reinforcing bar, points to a potentially critical problem which needs further investigation. Common ultimate strain levels in M57, $420 \mathrm{MPa}$ (Grade 60, \#18) bars are in a range from 7 to $12 \%$. Introducing an $450 \mathrm{~mm}$ radius bent in a M57 (\#18) bar causes strain levels of D/(2R) = $2.25 /(2 \times 18)=6.25 \%$, which is close to the ultimate strain range. The very low strain reserves and possible strain aging effects which raise the notch ductile temperature at which steel will fail in a brittle mode can cause sudden failure in these bent bars at very low additional strain levels.
The above examples of seismic damage encountered in concrete bridges have shown that most damage patterns can be identified by simple capacity checks or traced by diagnostic nonlinear finite element models. However, the detailed assessment to determine the actual structural state for repair or seismic retrofit requires additional considerations which are summarized in the remainder of this paper. 


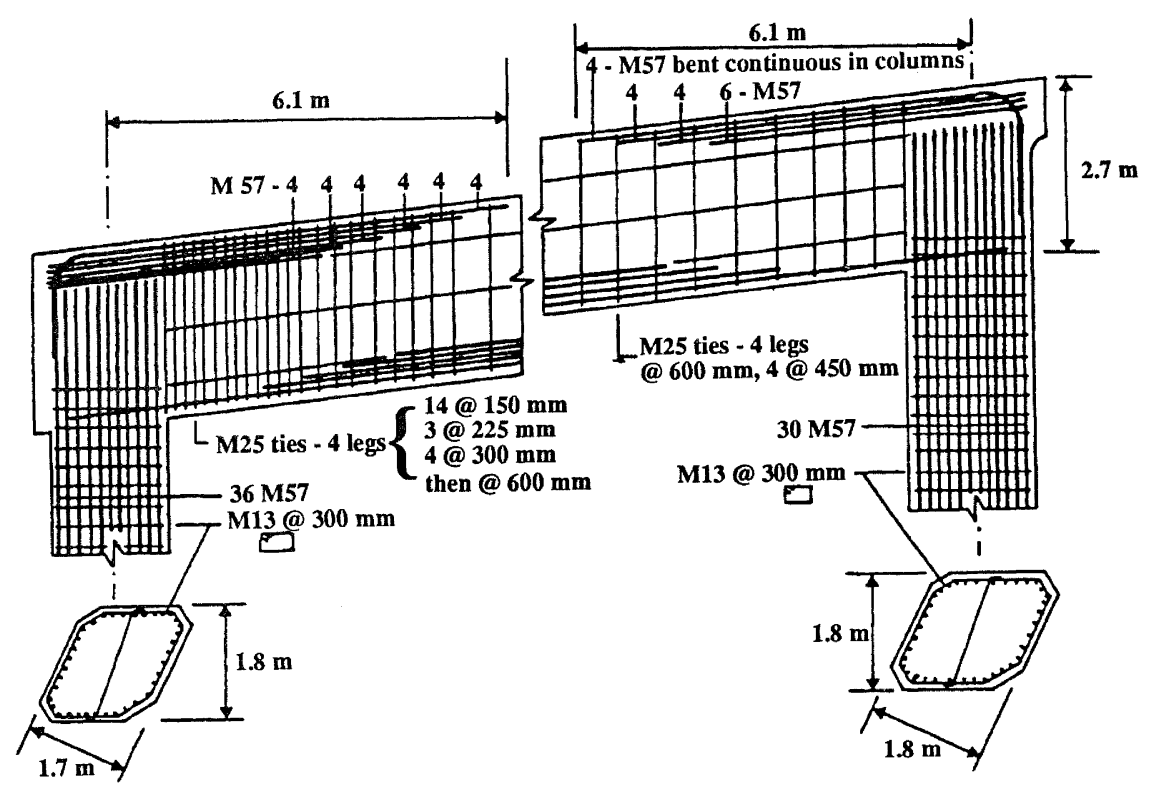

FIGURE 4 China Basin, Bent $\mathrm{N}_{1}-35$ Reinforcement.

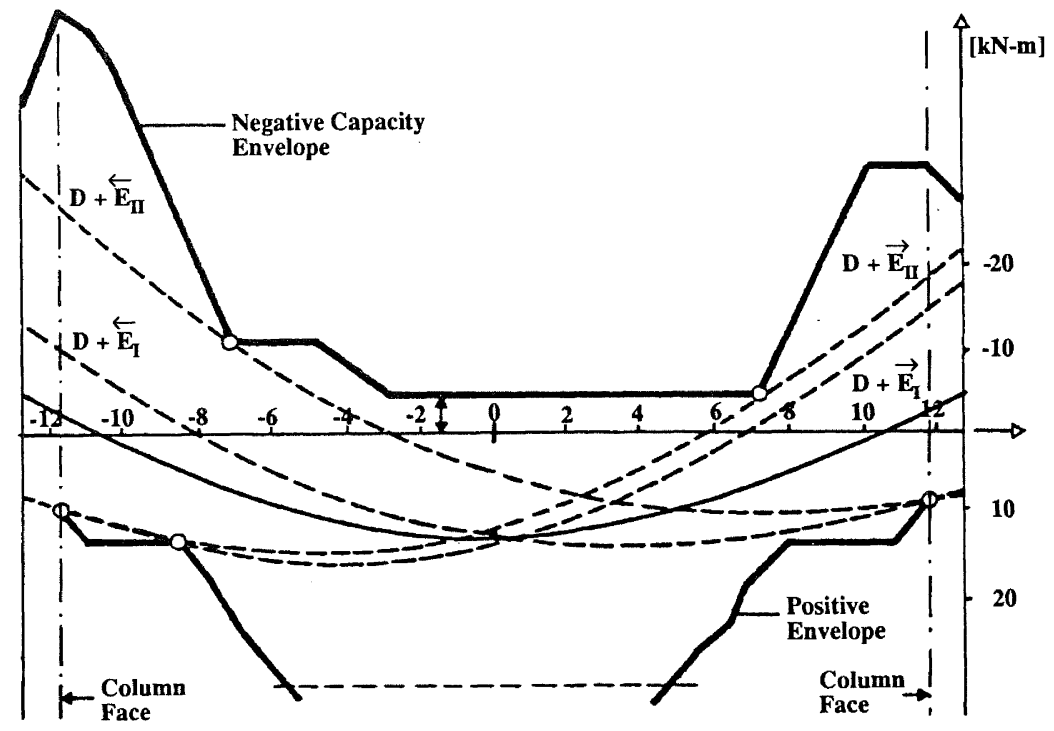

FIGURE 5 China Basin, Bent $\mathrm{N}_{1}-35$, Moment Capacities and Demand.

\section{SEISMIC PERFORMANCE ASSESSMENT}

\section{General Assessment Approach}

To assess the expected seismic performance of a structural concrete bridge bent, a state or capacity determination of structural components and systems needs to be performed with consideration of (1) actual material properties at the time of evaluation, i.e. probable concrete strength, not the design strength $f_{c}^{\prime}$, and actual stress strain behaviour for the reinforcement, not nominal specified design yield levels, (2) proper consideration of axial load effects, (3) proper consideration of possible confinement effects from transverse reinforcement, (4) reduced concrete shear contribution in potential plastic hinge regions and (5) realistic bond and anchorage estimates, particularly for large diameter reinforcing bars. A preliminary performance assessment of individual bridge bents and frames comprises the following general steps: Step I: Realistic member capacities based on the above considerations are derived for both flexure and shear, and the critical member failure mechanism is determined by direct comparison of the shear capacity with the plastic flexural limit state shear $V_{p}$ derived from the appropriate flexural plastic hinge failure model of the member. If $V_{p}$ is larger than the calculated shear capacity, a potentially brittle shear failure can be expected without the formation of ductile flexural plastic hinge mechanisms. Step II: Based on the probable member failure mechanisms, the expected global collapse mechanism for the complete bent or frame system is derived by comparing incrementally combined dead load and lateral seismic force 


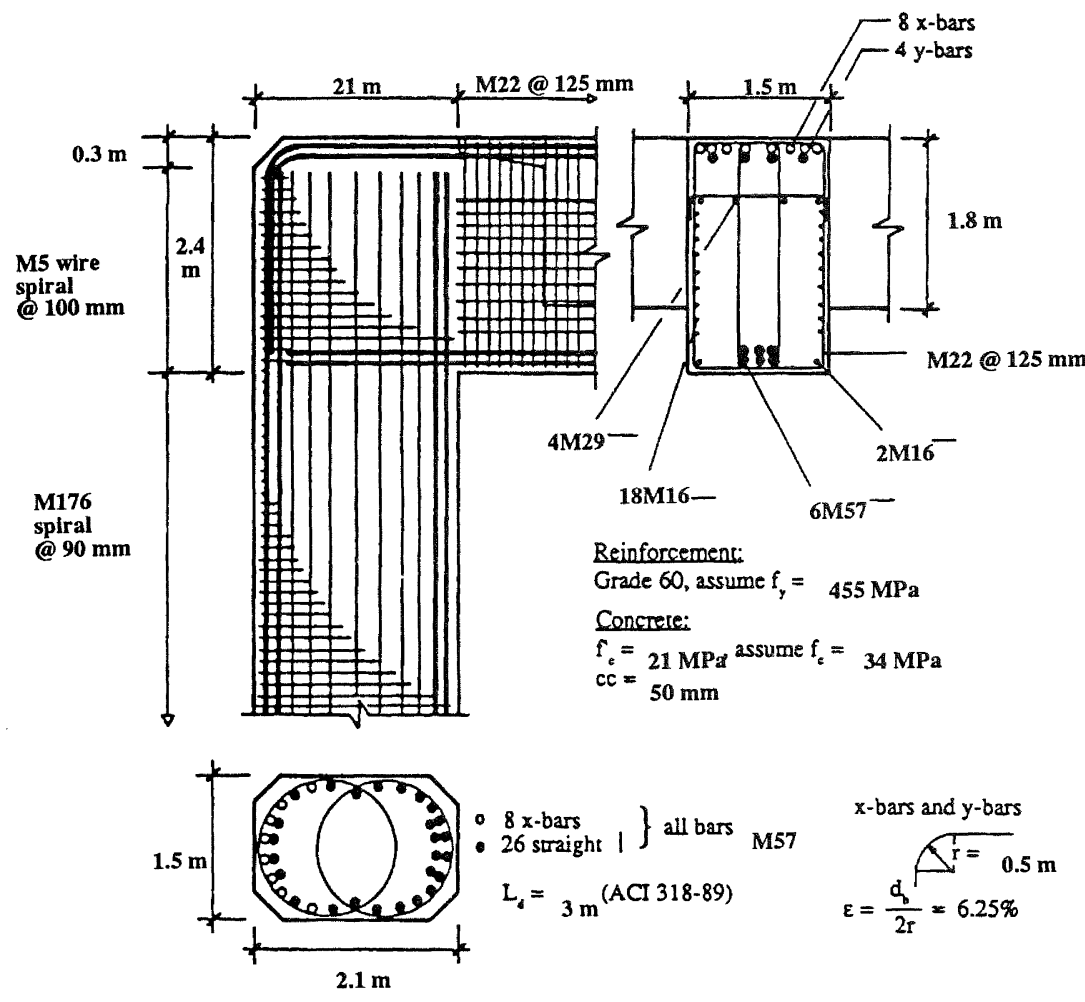

FIGURE 6 I-980, Bent No.38 Reinforcement Details.

action with the derived capacities. Step III: From the identified systems collapse mechanism, critical joint forces can now be determined at the collapse state and a direct comparison with most probable joint capacities will indicate if joint distress degrades the capacity of the collapse mechanism or if the joints behave as ideally assumed within or close to the elastic range. Step IV: Foundation and footing capacities are checked based on the derived critical bent mechanism. Finally, equivalent seismic base shear forces can be estimated corresponding to the lateral force level which causes collapse based on the above failure mechanism. Excessive joint distress can lead to a reduction of this base shear coefficient, particularly when a large number of cyclic load reversals and the associated joint degradation is considered.

Application of the above preliminary seismic assessment procedure to the San Francisco double-deck bridge bents has shown that particularly the joints did not meet design criteria for earthquake resistant ductile structures summarized by Paulay et al. [4] as: (1) joint strength should exceed the maximum strength of the weakest connecting member, (2) structure capacity should not be jeopardized by strength degradation in the joint, and (3) joint response should be elastic during moderate seismic disturbances.

Detailed criteria for an in-depth seismic assessment of existing concrete bridge structures are provided in the following evolving procedure summary developed in [6].

\section{Evolving Assessment Concepts}

(a) Analysis - Evolving practice should place more importance on "stand-alone" analyses of sections of superstructure between movement joints rather than elastic modal analyses of the entire structure. There is doubt about the value of results based on the assumption of elastic response with all pier bases subjected to coherent in-phase ground motion, when these bases may be separated by distances equivalent to many seismic wave lengths. Some current research emphasis is being given to bridge response under non-coherent ground acceleration inputs.

"Stand-alone" analyses look at the strength of collapse mechanisms, using simple frame models. Global modal analyses, or dynamic inelastic time-history analyses may be used to estimate displacements of the retrofitted structure. Foundation flexibility effects should be modeled by elastic or inelastic Winkler foundation springs.

Member stiffnesses are assessed on the basis of probability of cracking when the strength of the structure is achieved. Thus prestressed superstructure elements may be modeled by grosssection properties, while ductile columns will have cracked stiffness properties based on initial moment-curvature analyses of critical sections, assessed at first yield of the tension reinforcement. 
(b) Flexural Strength - Flexural strength determinations should be based on a realistic assessment of material properties (i.e., a $50 \%$ increase of concrete strength and a $10 \%$ increase of reinforcement yield strength above specified values). For capacity demand determinations for adjacent elements, possible overstrength in the reinforcement should be assessed based on a moment-curvature analysis incorporating strain-hardening. A realistic concrete compression stress-strain relationship should be employed, such as the Mander model [5], taking effects of confinement on the flexural strength into account. Flexural strength of sections with lapped splices are evaluated by use of a maximum reinforcement stress calculated from first principles based on the mechanics of lap splice crack formations. Details are given elsewhere.

(c) Flexural Ductility - Flexural ductility estimates should be based on calculating the plastic rotational capacities of individual hinges. These enable structural displacement ductilities to be determined from geometrical considerations and the elastic yield displacements. The plastic rotation $\theta_{\mathrm{p}}$ is defined as

$$
\begin{aligned}
& \theta_{\mathrm{p}}=\left(\phi_{\mathrm{u}}-\phi_{\mathrm{y}}\right) \mathrm{L}_{\mathrm{p}} \\
& \phi_{\mathrm{u}}=\epsilon_{\mathrm{cu}} / \mathrm{c} \\
& \epsilon_{\mathrm{cu}}=0.004+\frac{1.4 \rho_{\mathrm{s}} \mathrm{f}_{\mathrm{yh}} \epsilon_{\mathrm{sm}}}{\mathrm{f}_{\mathrm{cc}}^{\prime}} \geq 0.005 \\
& \mathrm{~L}_{\mathrm{p}}=0.08 \mathrm{~L}+\chi \mathrm{d}_{\mathrm{b}}
\end{aligned}
$$

where $\phi_{y}, \phi_{u}$ are yield and ultimate curvatures, respectively, $L_{p}$ is the equivalent plastic hinge length, $\mathrm{d}_{b}$ is the longitudinal bar diameter, and the factor $\chi$, taken as 6 for grade $40(275 \mathrm{MPa})$ and as 9 for grade $60(414 \mathrm{MPa})$ reinforcement, allows for extension of the plastic hinge into the supporting member by strain penetration. Equation (3) is a conservative estimate of the ultimate compression strain based on Mander's energy balance approach [5], where $\rho_{\mathrm{s}}$ is the volumetric ratio of transverse reinforcement with yield strength $\mathrm{f}_{\mathrm{yh}}$, and with strain at ultimate stress of $\epsilon_{\mathrm{sm}}$. For properly anchored transverse reinforcement, $\epsilon_{\mathrm{sm}}$ may conservatively be taken as 0.15 and 0.12 for grades 40 and 60 reinforcement, respectively; $\mathrm{f}_{\mathrm{cc}}{ }^{\prime}$ is the strength of the confined concrete, which may be taken as $1.5 f_{c}^{\prime}$ in lieu of a more exact analysis ${ }^{()}$.

Experimental evidence indicates that the flexural strength of columns with lap splices in the potential plastic hinge region degrades rapidly to a value equal to that which can be sustained by the axial compression force on the column, with no contribution from reinforcement. From this, the model describing flexural strength and ductility of a lap failure, shown in Fig.7a, is proposed, where strength degrades from the maximum, as calculated above, at $\mu=1$ to the gravity load moment at $\mu=3$. Although experimental evidence indicates that higher ductilities could be sustained, $\mu=3$ is felt to be a reasonable upper limit for dependable performance.

The plastic sway analysis identifies which plastic hinges are critical, and what the overall structural displacement ductility is. Hence the equivalent level of ground excitation can be determined.

Shear Strength - The ratio of plastic moment capacity to nominal moment capacity is based on required section ductility and assessed maximum feasible material strengths. Generally the overstrength ratio is less than the 1.5 adopted in existing practice. Where appropriate, higher mode effects amplifying shear are to be considered.
Shear strength of beams is based on a modification of the ASCE/ACI Committee 426 equations, thus:

$$
\mathrm{V}_{\mathrm{n}}=\mathrm{v}_{\mathrm{c}} \mathrm{b}_{\mathrm{w}} \mathrm{d}+\frac{\mathrm{A}_{\mathrm{v}} \mathrm{f}_{\mathrm{y}} \mathrm{d}}{\mathrm{s}}+0.2 \mathrm{P}_{\mathrm{u}}
$$

where

$$
\mathrm{v}_{\mathrm{c}}=\left(0.07+10 \rho_{\mathrm{w}}\right) \sqrt{\mathrm{f}_{\mathrm{c}}^{\prime}} \leq 0.2 \sqrt{\mathrm{f}_{\mathrm{c}}^{\prime}}(\mathrm{MPa})
$$

where $\rho_{\mathrm{w}}$ is the ratio of longitudinal tension reinforcement to effective web area. Equation (5) is applicable for displacement ductility factors of $\mu \leq 2$. For $\mu \geq 4, v_{c}=0$, and $2 \leq \mu \leq 4$, a linear interpolation is adopted (see Fig.7b). Note that the axial load term is appropriate for bridge cap beams, which may be subjected to significant axial tension or compression. Axial prestress is treated as a compressive force, and some allowance for $v_{c}$ in plastic hinges of prestressed members is made, provided prestress is not lost due to inelastic steel strains. The separation of $P_{u}$ from the $v_{c}$ term, with which it is more commonly associated, provides a greater emphasis on the axial force, and better agreement with experimental results.

For columns with well distributed reinforcement, Eq.(6) is unduly conservative. Recent testing on circular and rectangular columns indicates that the following values may be used: for nonductile regions, and for plastic hinges with $\mu \leq 2$,

$$
\mathrm{v}_{\mathrm{c}}=0.3 \sqrt{\mathrm{f}_{\mathrm{c}}^{\prime}}(\mathrm{MPa})
$$

and for plastic hinges with $\mu \geq 4$,

$$
\mathrm{v}_{\mathrm{c}}=0.1 \sqrt{\mathrm{f}_{\mathrm{c}}^{\prime}}(\mathrm{MPa})
$$

A linear interpolation between $\mu=2$ and $\mu=4$ as shown in Fig. $7 \mathrm{~b}$ is proposed.

The degradation of shear strength with increasing flexural ductility may reduce the flexural ductility capacity below that calculated for the plastic hinge region. When shear strength is reached, the structure is assumed to have reached its ultimate mechanism state.

For circular columns, the second term in Eqn(5), representing the contribution of transverse reinforcement, is replaced by $\pi A_{s} f_{y} D^{\prime} /(2 s)$, where $D^{\prime}$ is the core diameter ${ }^{(6)}$.

Beam/Column Joint Shear Strength - A rational analysis is required to determine the joint shear stress, $v_{\mathrm{cj}}$. Joint shear cracking is assumed to develop at a diagonal tension stress of

$$
\mathrm{f}_{\mathrm{t}}=0.3 \sqrt{\mathrm{f}_{\mathrm{c}}^{\prime}}(\mathrm{MPa})
$$

This agrees well with values back-analyzed from damaged and undamaged joints in the Loma Prieta earthquake. Joint shear strength is found from

$$
V_{c}=v_{c j} A_{j}+A_{v} f_{y}
$$

where $A_{j}$ is the joint section area parallel to the applied shear force, and $A_{v}$ is the total area of joint shear reinforcement, parallel to the joint shear force, between the resultant tension and compression forces producing the joint shear. For $\mu \leq 1, v_{\mathrm{cj}}$ is the concrete joint shear stress, acting in conjunction with the average joint compression or tension force to produce a

principal diagonal tension stress of $0.3 \sqrt{\mathrm{f}_{\mathrm{c}}^{\prime}}$. . The joint shear strength of Eq.(9) is compared with joint shear force corresponding to the formation of a plastic hinge mechanism in the longitudinal or transverse direction of the frame under 

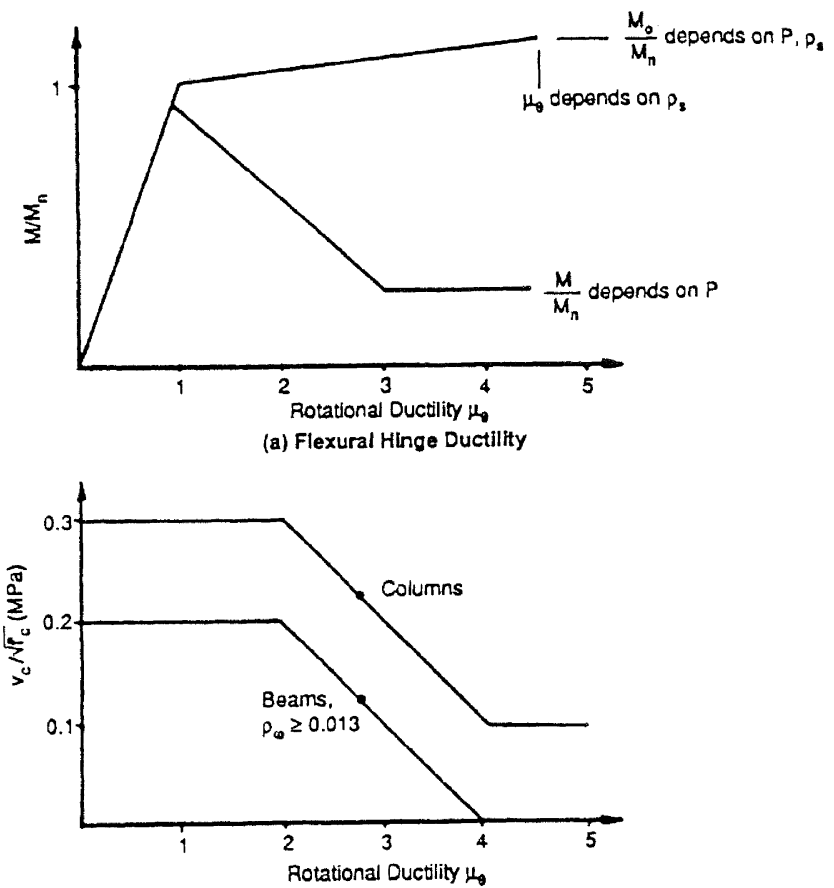

(b) Concrete Shear Strength in Plastic Hinges

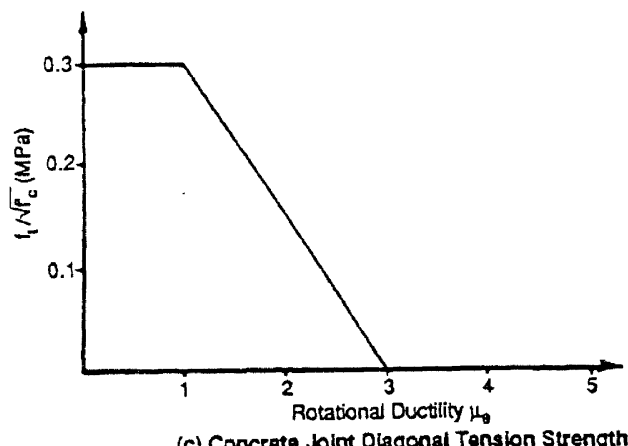

(c) Concrete Joint Dlagonal Tension Strength

FIGURE 7 Ductility of Inelastic Deformation Mechanisms Foundation Capacity.

consideration. If the shear strength is exceeded, the tension capacity of the joint is assumed to degrade from $0.3 \sqrt{\mathrm{f}_{\mathrm{c}}^{\prime}}$ to zero, as the adjacent number rotation increases to a value equivalent to $\mu_{\theta}=3$.

It should be pointed out that the above procedure is tentative and needs refinement based on experimental results. Relevant research is underway at UCSD.

Footings should be checked for flexural, shear and joint strength. Procedures for the latter are rudimentary at this stage, pending research results, since methods such as proposed above are known to underestimate capacity. One of the major problems is assessing the width of footing effective in resisting joint shear forces. It should be noted, however, that footing joint regions are generally not reinforced for joint shear forces, and joint failures have been observed in tests at UCSD.
Uplift of footings from tension piles, or uplift of tension piles is not necessarily considered "failure" even if capacity is significantly less than that corresponding to the plastic moment capacity of column hinges, since rocking mechanisms can limit seismic response of the superstructure. Deflections corresponding to rocking are estimated by dynamic inelastic analysis and the ability of the structure to sustain these levels is assessed. Liquefaction potential is assessed, and remedial measures considered.

\section{CONCLUSIONS}

The art of retrofitting bridge structures for enhanced seismic performance requires a much greater understanding of seismic response of structures than is necessary for new bridge design, where following codified provisions typically results in adequate performance without requiring detailed conceptual considerations. Experience with initial retrofit measures in California has shown that "cookbook" approaches are inadequate for retrofit designs. As a consequence, only the most knowledgeable and experienced designers should be involved in seismic retrofit. This requirement is emphasized by the fact that much of the bridge retrofit effort is proceeding ahead of the supportive research data. As a consequence, retrofit designers are forced into a situation where strategies must be determined based on theoretical and conceptual considerations. The consequences of poorly conceived retrofit strategies are costly schemes which will do little, if anything, to improve seismic resistance. The consequences of failures of retrofitted bridges will reflect not just on the individual designers, but on the bridge design community as a whole.

As a first step toward a consistent retrofit design a realistic assessment or state determination of the existing bridge structure is needed. An evolving procedure for a realistic performance assessment has been outlined.

\section{REFERENCES}

[1] Priestley, M.J.N. and Seible,F. 1990. "Assessment of Bridge Damage During the Loma Prieta Earthquake". Structural Systems Research Project, Report No.SSRP90/01.

[2] Schlaich,J., Schäfer,K. and Mattias,J. 1987. "Toward a Consistent Structural Concrete Design", PCI Journal, May-June: 74-150.

[3] Collins,M.P. 1978. "Towards a Rational Theory for RC Members in Shear". ASCE Journal of the Structural Division, 104: 649-666.

[4] Paulay,T., Park,R. and Priestley,M.J.N. 1978. "Reinforced Concrete Beam-Column Joints Under Seismic Actions", ACI Journal, 75: 585-593.

[5] Mander,J.B., Priestley, M.J.N. and Park R. 1988 "Theoretical Stress-Strain Behavior of Confined Concrete", ASCE Journal of the Structural Division, 114: $1827-1849$.

[6] Priestley, M.J.N. 'Seismic Assessment of Existing Concrete Bridges' in "Seismic Assessment and Retrofit of Bridges" M.J.N.Priestley and F.Seible Editors, Structural Systems Research Project Report No.SSRP 91/03, July 1991, pp 84-149. 